\title{
Prequalification of Construction Contractor using a FAHP
}

\author{
M. K. Trivedi \\ Department of Civil \\ Engineering \\ MITS, Gwalior, INDIA
}

\author{
M. K. Pandey \\ Department of Civil \\ Engineering \\ ITM, Gwalior, INDIA
}

\author{
S. S. Bhadoria \\ SGSITS \\ Indore, INDIA
}

\begin{abstract}
Analytical hierarchy process (AHP) as multiple criteria decision making tools can be used in the problems with spatial nature like selection of construction contractor. In this study the application of AHP and its weakness and strength and ultimately the fuzzy modified analytical hierarchy process (FAHP) is proposed after the concept of fuzziness, uncertainty and vagueness. A triangular fuzzy umber is considered to form a fuzzy comparison matrix for criteria and alternatives (contractors). Consequently a fuzzy score matrix is prepared to obtained crisp score (defuzzified value), which ultimately gives overall ratting of the alternatives (contractors). The construction industry is an integral part of infrastructural development of country. The selection of appropriate construction contractor is the multi criteria decision making process. In the large project it is very difficult for the decision makers to analyze the capabilities of contractors against vagueness, imprecision, inexact and qualitative criteria. These criteria can be best expressed in the linguistic terms, which cab be translated into mathematical measures by using multi criteria decision making techniques (AHP and FSM). In this paper, we present an effort to provide application of fuzzy analytical hierarchy process in the selection of contractor. To develop a fuzzy analytical hierarchy approach to rank the suitable contractor for the housing project.
\end{abstract}

\section{Keywords}

AHP, FAHP, FSM, decision making.

\section{INTRODUCTION}

In the present scenario of competition in the construction industry, the selection of appropriate construction contractor for the project is very important for the success of project. Selection of suitable contractor for any housing project is a complex and difficult decision making problem.

The selection of construction contractor in general is two stage problem. First is prequalification stage and second is bid evaluation stage. In the prequalification stage a large numbers of contractors are invited and analyzed, based on predetermined criteria and a short listed contractors is drawn by the clients. In the bid evaluation stage short listed contractors in the prequalification stage are again invited and investigated to select the appropriate contractor for the project. The contractors prequalification can be taken as external auditing of their capabilities in [1].

Prequalification is the screening of contractors by clients (owners) based on a set of criteria is presented in [2].
Multicriteria decision making problem involve six components are discussed in [3] an [4] as follows;

- A goal or a set of goals the decision makers want to achieve.

- The decision maker or a group of decision maker involved in the decision making process with their preferences with respect to the evaluation criteria.

- A set of evaluation criteria.

- A set of decision alternatives.

- A set of uncontrollable, uncertain ( independent) variables or states of nature ( decision environment) and

- The set of outcomes or consequences associated with each alternative attribute pair.

\subsection{Analytical hierarchy process (AHP)}

Analytical hierarchy process is a multicriteria decision technique that uses hierarchical structures to define a problem and then develop priorities for the alternatives based on the judgment of the user is given in [5].

In [6], the AHP procedure involves six steps.

- Define the unstructured problem

- Developing the AHP hierarchy

- Pair wise comparison

- Estimate the relative weights

- Check the consistency

- Obtain the overall ranking

The first step in the AHP method is to decompose the decision problem into a hierarchy that consist of the most important element of the decision problem in [7].

The relative importance of the decision elements is assessed indirectly from comparison judgments in the second step. The decision maker is required to provide his / her performance by comparing all criteria, sub criteria and alternatives with respect to upper level decision elements and construct a pair wise comparison matrix $(\boldsymbol{X})$ by using the relative scale measurements as shown in Table 1 .

$$
X=\left[\begin{array}{cccc}
1 & \frac{W_{1}}{W_{2}} \ldots \ldots \ldots & \frac{W_{1}}{W_{n}} \\
\frac{W_{2}}{W_{1}} & 1 \ldots \ldots \ldots \ldots & \frac{W_{2}}{W_{n}} \\
\frac{W_{n}}{W_{1}} & \frac{W_{n}}{W_{2}} \ldots \ldots \ldots & 1
\end{array}\right]
$$

In this matrix $W_{1}, W_{2}, \ldots \ldots \ldots W_{n}=$ weight of elements $1,2, \ldots \ldots, n$. 
Table 1. Scales of pair wise comparison

\begin{tabular}{|l|l|}
\hline $\begin{array}{l}\text { Preference in numeric } \\
\text { variables }\end{array}$ & $\begin{array}{l}\text { Preferences in linguistic } \\
\text { variables }\end{array}$ \\
\hline 1 & Equal importance \\
3 & Moderate importance \\
5 & Strong importance \\
7 & Very strong importance \\
9 & Extreme importance \\
$2,4,6,8$ & Intermediate values between \\
& adjacent scale values. \\
\hline
\end{tabular}

\subsection{Estimation of Relative Weights}

Some methods like eigenvector method and lease square method are used to compute the relative weights of elements in each pair wise comparison matrix.

\section{Determination of the consistency:}

The consistency is determined by using the eigenvalue $\lambda_{\max }$. calculate the consistency index, $\mathrm{CI}$ as follows

$$
C I=\frac{\left(\lambda_{\max }-n\right)}{n-1}
$$

The consistency ratio is calculated as

$$
C R=\frac{C I}{R I}
$$

Where $R I$ will be taken from the Table 2 on the basis of size of matrix. If the value of $C R$ is less than 0.10 , the judgments are consistent, if it is more, the judgments are inconsistent then the judgments should be reviewed to obtain consistence matrix.

Table 2. Random Inconsistency Indices

\begin{tabular}{|c|c|c|c|c|c|c|}
\hline $\begin{array}{c}\text { Size of } \\
\text { Matrix }\end{array}$ & 1 & 2 & 3 & 4 & 5 & 6 \\
\hline$R I$ & 0 & 0 & 0.58 & 0.9 & 1.12 & 1.24 \\
\hline
\end{tabular}

\subsection{Determine the overall rating}

In the last step the relative weights of decision elements are aggregated to obtain an overall rating for the alternatives as follows:

$$
W_{i}^{a}=\sum_{j=1}^{m} W_{i j}^{a} W_{j}^{c}
$$

Where $W_{i}^{a}=$ Total weight of alternative $i$

$W_{i j}^{a}=$ Weight of alternatives $i$ associated to criteria $c$.

$m=$ Number of criteria

$n=$ Number of alternatives.

\subsection{Fuzzy Analytical Hierarchy Process ( FAHP):}

In spite of popularity of AHP, this method is often criticized for its inability to adequately handle inherent uncertainty and imprecision associated with the mapping of the decision maker's perception to exact numbers in [8]. Since fuzziness and vagueness are common characteristics in most of the decision making problems, a fuzzy AHP method can able to tolerate vagueness or ambiguity presented in [9]. The conventional AHP approach may not fully reflect a style of human thinking because the decision maker usually feel more confident to give interval judgments rather than expressing their judgments in the form of single numeric values and so FAHP is capable of capturing a human's appraisal of ambiguity when complex multi criteria decision making problems are considered in [10]. This ability comes to exist when the crisp judgment transformed into fuzzy judgments. In modeling, a real life problems, trapezoidal and triangular fuzzy numbers are used in [11] and [12].

In the proposed work triangular fuzzy number is used. A triangular fuzzy number is defined by three real numbers $a \leq b \leq c$ and the membership function for triangular fuzzy number is defined as;

$$
\mu_{A}(X)=\left\{\begin{array}{cl}
\frac{(x-a)}{(b-a)} & a \leq x \leq b \\
\frac{(c-x)}{(c-a)} & b \leq x \leq c \\
0 & \text { Otherwise }
\end{array}\right.
$$

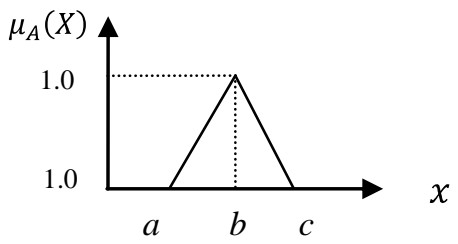

Fig 1: Fuzzy Triangular Number and Membership Function

In the next step of decision making process, weights of all criteria and scores of alternatives are to be calculated from fuzzy pair wise comparison matrices of the type (1) as depicted in Fig. 2.

\subsection{Determination of weights $\left(w_{j}^{c}\right)$ for criteria}

The fuzzy comparison judgments given by the experts to each of the decision criteria and the average fuzzy scores, defuzzified values and normalized weights of criteria are obtained and same are given in the Table 3.

Case study: Six criteria are chosen for evaluation of alternative construction contractors, namely post experience, financial turnover, past performance, man power resource, plant and equipment resource and similar projects in hand. Five alternative construction contractors are indentified as potential construction contractions. The goal is to select an appropriate contractor for the specific project, satisfying all criteria in the best way.

The proposed methodology is the modification of AHP method,

the first step in applying the fuzzy AHP is to construct a hierarchy of alternative contractors and criteria as shown in Fig 2. 


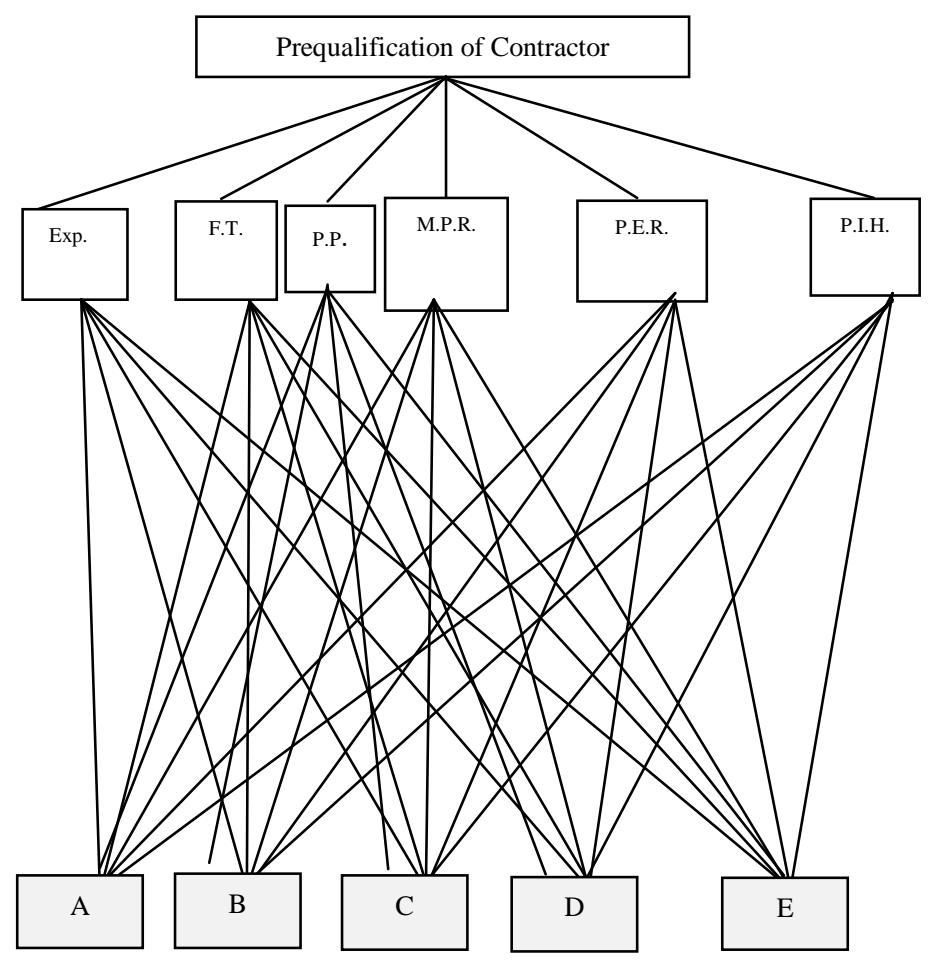

\subsection{Determination of weights $\left(w_{i j}^{a}\right)$ for alternatives}

Fuzzy pairwise matrix for past experience, financial turnover, past performance, man power resources, plant and equipment resources and similar projects in hand are prepared on the basis of fuzzy comparision judgements given by the experts to the alternatives (contractors) and the average fuzzy scores, defuzzified values and normalized. weights of alternatives are obtained as shown in Table 4, 5, 6, 7, 8, 9.

\subsection{Decision Matrix for Contractor Pre- qualification}

The weights of criteria $W_{j}^{c}$ and the weights of each alternatives $W_{i j}^{a}$

relative to each criteria are combined in order to determine the overall ranking of the contractors, using equation 4 . The results are shown in Table 10.

Fig 2: Hierarchical structure of decision problem

\begin{tabular}{|c|c|c|c|c|c|c|}
\hline \multicolumn{7}{|c|}{ Table 3. Fuzzy Pairwise Comparison Matrix for the Criteria } \\
\hline Criteria & Exp. & F.T & P.P & M.P.R & P.E.R & P.I.H \\
\hline Exp. & $(1,1,1)$ & $(1,2,3)$ & $(3,4,5)$ & $(4,5,6)$ & $(5,6,7)$ & $(4,5,6)$ \\
\hline F.T & $(1 / 3,1 / 2,1)$ & $(1,1,1)$ & $(2,3,4)$ & $(6,7,8)$ & $(6,7,8)$ & $(4,5,6)$ \\
\hline P.P & $(1 / 5,1 / 4,1 / 3)$ & $(1 / 4,1 / 3,1 / 2)$ & $(1,1,1)$ & $(2,3,4)$ & $(2,3,4)$ & $(3,4,5)$ \\
\hline M.P.R & $(1 / 6,1 / 5,1 / 4)$ & $(1 / 8,1 / 7,1 / 6)$ & $(1 / 4,1 / 3,1 / 2)$ & $(1,1,1)$ & $(1,2,3)$ & $(1 / 4,1 / 3,1 / 2)$ \\
\hline P.E.R & $(1 / 7,1 / 6,1 / 5)$ & $(1 / 8,1 / 7,1 / 6)$ & $(1 / 4,1 / 3,1 / 2)$ & $(1 / 3,1 / 2,1)$ & $(1,1,1)$ & $(1 / 4,1 / 3,1 / 2)$ \\
\hline P.I.H & $(1 / 6,1 / 5,1 / 4)$ & $(1 / 6,1 / 5,1 / 4)$ & $(1 / 5,1 / 4,1 / 3)$ & $(2,3,4)$ & $(2,3,4)$ & $(1,1,1)$ \\
\hline
\end{tabular}

\begin{tabular}{|l|l|l|l|c|c|}
\hline Criteria & \multicolumn{3}{|c|}{ Average fuzzy scores } & Defuzzified values & $\begin{array}{c}\text { Normalized } \\
\text { weight }\end{array}$ \\
\hline Exp. & 3.000 & 3.833 & 4.666 & 3.833 & 0.317 \\
\hline F.T & 3.222 & 3.916 & 4.666 & 3.930 & 0.325 \\
\hline P.P & 1.048 & 1.930 & 2.472 & 1.935 & .160 \\
\hline M.P.R & 0.465 & 0.668 & 0.902 & 0.675 & 0.055 \\
\hline P.E.R & 0.350 & 0.412 & 0.561 & 0.433 & 0.035 \\
\hline P.I.H & 0.922 & 1.275 & 1.638 & 1.277 & 0.105 \\
\hline
\end{tabular}




\begin{tabular}{|c|c|c|c|c|c|}
\hline \multicolumn{7}{|c|}{ Table 4. Fuzzy Pairwise Comparison Matrix for Experience } \\
\hline Alternative & A & B & C & D & E \\
\hline A & $(1,1,1)$ & $(2,3,4)$ & $(4,5,4)$ & $(1 / 6,1 / 5,1 / 4)$ & $(2,3,4)$ \\
\hline B & $(1 / 4,1 / 3,1 / 2)$ & $(1,1,1)$ & $(1,2,3)$, & $(1 / 5,1 / 4,1 / 3)$ & $(3,4,5)$ \\
\hline C & $(1 / 6,1 / 5,1 / 4)$ & $(1 / 3,1 / 2,1)$ & $(1,1,1)$ & $(1 / 6,1 / 5,1 / 4)$ & $(1,2,3)$ \\
\hline D & $(4,5,6)$ & $(3,4,5)$ & $(4,5,6)$ & $(1,1,1)$ & $(6,7,8)$ \\
\hline E & $(1 / 4,1 / 3,1 / 2)$ & $(1 / 5,1 / 4,1 / 3)$ & $(1 / 3,1 / 2,1)$ & $(1 / 8,1 / 7,1 / 6)$ & $(1,1,1)$ \\
\hline
\end{tabular}

\begin{tabular}{|c|c|c|c|c|c|}
\hline Alternative & \multicolumn{3}{|c|}{ Average fuzzy scores } & Defuzzified values & Normalized weight \\
\hline $\mathrm{A}$ & 1.833 & 2.440 & 3.050 & 2.440 & 0.256 \\
\hline B & 1.090 & 1.516 & 1.966 & 1.522 & 0.160 \\
\hline $\mathrm{C}$ & 0.533 & 0.580 & 1.100 & 0.698 & 0.073 \\
\hline $\mathrm{D}$ & 3.600 & 4.400 & 5.200 & 4.400 & 0.461 \\
\hline $\mathrm{E}$ & 0.381 & 0.445 & 0.600 & 0.467 & 0.049 \\
\hline
\end{tabular}

\begin{tabular}{|c|c|c|c|c|c|}
\hline \multicolumn{7}{|c|}{ Table 5. Fuzz Pairwise Comparison Matrix for Turnover } \\
\hline Alternative & A & B & C & D & E \\
\hline A & $(1,1,1)$ & $(2,3,4)$ & $(3,4,5)$ & $(1 / 5,1 / 4,1 / 3)$ & $(3,4,5)$ \\
\hline B & $(1 / 4,1 / 3,1 / 2)$ & $(1,1,1)$ & $(1,2,3)$ & $(1 / 5,1 / 4,1 / 3)$ & $(4,5,6)$ \\
\hline C & $(1 / 5,1 / 4,1 / 3)$ & $(1 / 3,1 / 2,1)$ & $(1,1,1)$ & $(1 / 5,1 / 4,1 / 3)$ & $(2,3,4)$ \\
\hline D & $(3,4,5)$ & $(3,4,5)$ & $(3,4,5)$ & $(1,1,1)$ & $(4,5,6)$ \\
\hline E & $(1 / 5,1 / 4,1 / 3)$ & $(1 / 6,1 / 5,1 / 4)$ & $(1 / 3,1 / 2,1)$ & $(1 / 6,1 / 5,1 / 4)$ & $(1,1,1)$ \\
\hline
\end{tabular}

\begin{tabular}{|c|c|c|c|c|c|}
\hline Alternatives & \multicolumn{3}{|c|}{ Average Fuzzy Scores } & Defuzzified Values & Normalized Weights \\
\hline A & 1.840 & 2.450 & 3.066 & 2.451 & 0.266 \\
\hline B & 1.290 & 1.716 & 2.166 & 1.722 & 0.187 \\
\hline C & 0.746 & 1.000 & 1.333 & 1.019 & 0.391 \\
\hline D & 2.800 & 3.600 & 4.400 & 3.600 & 0.0493 \\
\hline E & 0.356 & 0.396 & 0.466 & 0.4103 & 0.110 \\
\hline
\end{tabular}

\begin{tabular}{|c|c|c|c|c|c|}
\hline \multicolumn{7}{|c|}{ Table 6. Fuzzy Pairwise Comparison Matrix for Experience } \\
\hline Alternative & A & B & C & D & E \\
\hline A & $(1,1,1)$ & $(2,3,4)$ & $(1 / 5,1 / 4,1 / 3)$ & $(1 / 4,1 / 3,1 / 2)$ & $(4,5,6)$ \\
\hline B & $(1 / 4,1 / 3,1 / 2)$ & $(1,1,1)$ & $(1 / 4,1 / 3,1 / 2)$ & $(1 / 5,1 / 4,1 / 3)$ & $(5,4,3)$ \\
\hline C & $(5,4,3)$ & $(2,3,4)$ & $(1,1,1)$ & $(1,2,3)$ & $(4,5,6)$ \\
\hline D & $(2,3,4)$ & $(3,4,5)$ & $(1 / 3,1 / 2,1)$ & $(1,1,1)$ & $(4,5,6)$ \\
\hline E & $(1 / 6,1 / 5,1 / 4)$ & $(1 / 5,1 / 4,1 / 3)$ & $(1 / 6,1 / 5,1 / 4)$ & $(1 / 6,1 / 5,1 / 4)$ & $(1,1,1)$ \\
\hline
\end{tabular}




\begin{tabular}{|c|c|c|c|c|c|}
\hline Alternative & \multicolumn{3}{|c|}{ Average fuzzy scores } & Defuzzified values & Normalized weight \\
\hline A & 1.490 & 1.916 & 2.366 & 1.922 & 0.201 \\
\hline B & 1.340 & 1.183 & 1.066 & 1.193 & 0.125 \\
\hline C & 2.600 & 3.000 & 3.400 & 3.000 & 0.314 \\
\hline D & 2.066 & 2.700 & 3.400 & 2.716 & 0.286 \\
\hline E & 1.700 & 0.370 & 0.416 & 0.714 & 0.074 \\
\hline
\end{tabular}

\begin{tabular}{|c|c|c|c|c|c|}
\hline \multicolumn{7}{|c|}{ Table 7. Fuzzy Pairwise Comparison Matrix for Turnover } \\
\hline Alternative & A & B & C & D & E \\
\hline A & $(1,1,1)$ & $(1 / 4,1 / 3,1 / 2)$ & $(1 / 3,1 / 2,1)$ & $(1 / 5,1 / 4,1 / 3)$ & $(3,4,5)$ \\
\hline B & $(2,3,4)$ & $(1,1,1)$ & $(1,2,3)$ & $(1 / 5,1 / 4,1 / 3)$ & $(3,4,5)$ \\
\hline C & $(1,2,3)$ & $(1 / 3,1 / 2,1)$ & $(1,1,1)$ & $(1,2,3)$ & $(3,4,5)$ \\
\hline D & $(3,4,5)$ & $(1 / 3,1 / 2,1)$ & $(1,2,3)$ & $(1,1,1)$ & $(4,5,6)$ \\
\hline E & $(1 / 5,1 / 4,1 / 3)$ & $(1 / 5,1 / 4,1 / 3)$ & $(1 / 4,1 / 3,1 / 2)$ & $(1 / 6,1 / 5,1 / 4)$ & $(1,1,1)$ \\
\hline
\end{tabular}

\begin{tabular}{|c|c|c|c|c|c|}
\hline Alternatives & \multicolumn{3}{|c|}{ Average Fuzzy Scores } & Defuzzified Values & Normalized Weights \\
\hline A & 0.956 & 1.216 & 1.566 & 1.238 & 0.154 \\
\hline B & 1.600 & 2.400 & 3.200 & 2.400 & 0.300 \\
\hline C & 0.933 & 1.400 & 2.000 & 1.433 & 0.180 \\
\hline D & 1.866 & 2.500 & 3.200 & 2.516 & 0.314 \\
\hline E & 0.363 & 0.406 & 0.483 & 0.414 & 0.051 \\
\hline
\end{tabular}

\begin{tabular}{|c|c|c|c|c|c|}
\hline \multicolumn{6}{|c|}{ Table 8. Fuzzy Pairwise Comparison Matrix for Plant and Equipment Resources } \\
\hline Alternative & A & B & C & D & E \\
\hline A & $(1,1,1)$ & $(2,3,4)$ & $(1 / 4,1 / 3,1 / 2)$ & $(1 / 5,1 / 4,1 / 3)$ & $(4,5,6)$ \\
\hline B & $(1 / 4,1 / 3,1 / 2)$ & $(1,1,1)$ & $(1 / 4,1 / 3,1 / 2)$ & $(1 / 6,1 / 5,1 / 4)$ & $(5,6,7)$ \\
\hline C & $(2,3,4)$ & $(2,3,4)$ & $(1,1,1)$ & $(1 / 5,1 / 4,1 / 3)$ & $(8,9,10)$ \\
\hline D & $(3,4,5)$ & $(4,5,6)$ & $(3,4,5)$ & $(1,1,1)$ & $(8,9,10)$ \\
\hline E & $(1 / 6,1 / 5,1 / 4)$ & $(1 / 7,1 / 6,1 / 5)$ & $(1 / 10,1 / 9,1 / 8)$ & $(10,9,8)$ & $(1,1,1)$ \\
\hline
\end{tabular}

\begin{tabular}{|c|c|c|c|c|c|}
\hline Alternatives & \multicolumn{3}{|c|}{ Average Fuzzy Scores } & Defuzzified Values & Normalized Weights \\
\hline A & 1.490 & 1.916 & 2.366 & 1.922 & 0.164 \\
\hline B & 1.333 & 1.573 & 1.850 & 1.582 & 0.135 \\
\hline C & 2.460 & 3.250 & 3.866 & 3.251 & 0.278 \\
\hline D & 3.800 & 4.600 & 5.400 & 4.600 & 0.394 \\
\hline E & 0.302 & 0.317 & 0.340 & 0.391 & 0.027 \\
\hline
\end{tabular}




\begin{tabular}{|c|c|c|c|c|c|}
\hline \multicolumn{7}{|c|}{ Table 9. Fuzzy Pairwise Comparison Matrix for Projects in Hand } \\
\hline Alternative & A & B & C & D & E \\
\hline A & $(1,1,1)$ & $(3,4,5)$ & $(1,2,3)$ & $(1,2,3)$ & $(2,3,4)$ \\
\hline B & $(1 / 5,1 / 4,1 / 3)$ & $(1,1,1)$ & $(1 / 4,1 / 3,1 / 2)$ & $(1 / 5,1 / 4,1 / 3)$ & $(1,2,3)$ \\
\hline C & $(1 / 3,1 / 2,1)$ & $(2,3,4)$ & $(1,1,1)$ & $(1 / 5,1 / 4,1 / 3)$ & $(2,3,4)$ \\
\hline D & $(1 / 3,1 / 2,1)$ & $(3,4,5)$ & $(3,4,5)$ & $(1,1,1)$ & $(4,5,6)$ \\
\hline E & $(1 / 4,1 / 3,1 / 2)$ & $(1 / 3,1 / 2,1)$ & $(1 / 4,1 / 3,1 / 2)$ & $(1 / 6,1 / 5,1 / 4)$ & $(1,1,1)$ \\
\hline
\end{tabular}

\begin{tabular}{|c|c|c|c|c|c|}
\hline Alternatives & \multicolumn{3}{|c|}{ Average Fuzzy Scores } & Defuzzified Values & Normalized Weights \\
\hline A & 1.600 & 2.400 & 3.200 & 2.400 & 0.296 \\
\hline B & 0.530 & 0.766 & 1.033 & 0.773 & 0.095 \\
\hline C & 1.066 & 1.550 & 2.066 & 1.558 & 0.191 \\
\hline D & 2.266 & 2.900 & 3.600 & 2.916 & 0.358 \\
\hline E & 0.400 & 0.473 & 0.650 & 0.500 & 0.061 \\
\hline
\end{tabular}

\begin{tabular}{|c|c|c|c|c|c|c|c|c|}
\hline \multicolumn{9}{|c|}{ Table 10. Decision Matrix for Contractor Pre-qualification } \\
\hline Alternative & $\begin{array}{c}\text { Exp. } \\
\mathbf{( 0 . 3 1 7 )}\end{array}$ & $\begin{array}{c}\text { F.T. } \\
\mathbf{( 0 . 3 2 5})\end{array}$ & $\begin{array}{c}\text { P.P. } \\
\mathbf{( 0 . 1 6 0 )}\end{array}$ & $\begin{array}{c}\text { M.P.R. } \\
\mathbf{( 0 . 0 5 5})\end{array}$ & $\begin{array}{c}\text { P.E.R. } \\
\mathbf{( 0 . 0 3 5}\end{array}$ & $\begin{array}{c}\text { P.I.H. } \\
\mathbf{( 0 . 1 0 5})\end{array}$ & $\begin{array}{c}\text { Overall } \\
\text { Priority } \\
\text { Vectors }\end{array}$ & $\begin{array}{c}\text { Order of } \\
\text { Ranking }\end{array}$ \\
\hline A & 0.256 & 0.266 & 0.201 & 0.154 & 0.164 & 0.294 & 0.245 & 2 \\
\hline B & 0.160 & 0.187 & 0.125 & 0.300 & 0.135 & 0.950 & 0.162 & 3 \\
\hline C & 0.073 & 0.110 & 0.314 & 0.180 & 0.278 & 0.191 & 0.148 & 4 \\
\hline D & 0.610 & 0.391 & 0.284 & 0.314 & 0.394 & 0.358 & 0.387 & 1 \\
\hline
\end{tabular}

\section{RESULTS AND DISCUSSION}

From the various calculation done using the fuzzy analytical hierarchy process, for prequalification, the order of ranking of contractors are as $D>A>B>C>E$. The result shows that $D$ is the best qualified construction contractor to perform the project. Since, fuzziness and vagueness are common characteristics in most of the decision making problems, a fuzzy AHP can able to tolerate vagueness and ambiguity. The conventional AHP may not fully reflect a style of human thinking because the decision maker usually feel more confident to give internal judgments (Fuzzy judgment) rather then a single numeric values (Crisp Judgment).

\section{CONCLUSION}

The conventional AHP approach may not fully reflect a style of human thinking because the decision maker usually feel more confident to give interval judgments rather than expressing their judgments in the form of single numeric values (crisp value) therefore FAHP is capable of capturing a human's appraised of ambiguity when complex multicriteria decision making problems are considered. This ability comes to exist when the crisp judgments transformed into fuzzy judgment. Results are shown that efficacy of proposed approach using FAHP. In future, we will enhance our proposed model by more construction constraints and environmental scenarios.

\section{ACKNOWLEDGMENTS}

Our special thanks to Mr. Brijesh Kumar Chaurasia and contractors, who have contributed towards development of this research work. 


\section{REFERENCES}

[1] Bubshait, A.A. and AL-Globali, H. (1996). Contractor Prequalification in Saudi Arabia. J. Manage. Engg. 12(2), $50-54$.

[2] Sonmez, M., Holt, G.D., Yang, J.B. and Graham, G. (2002). Applying Evidential Reasoning to Prequalifying Construction Contractors. J. Manage. Engg. 18(3), 111 119.

[3] Pitz, G.F. and Mckillip, J. (1984). Decision Analysis for Program Evaluation. Sage Publication. Thousand Oaks. CA

[4] Keeney, R. and Raffia, H. (1976). Decision with Multiple Objectives. Cambridge University Press. Cambridge.

[5] Satty, T.L. (1980). The Analytic Hierarchy Process : Planning, Priority Setting, Resource Allocation. McGraw Hill. New York. NY. 437

[6] Lee, A.H.I., Chen, W.C., Chang, C.J. (2008). A Fuzzy AHP and BSC Approach for Evaluating Performance of IT Department in the Manufacturing Industry in Taiwan Expert Systems with Applications. 34. 96 - 107.
[7] Boroushaki, S., Malczewski, J. (2008). Implementing an Extension of the Analytical Hierarchy Process using Order Weighted Averaging Operators with Fuzzy Quantifiers ArcGIS Computers and Geoscience. 34. 399 - 410

[8] Deng, H. (1990). Multicriteria Analysis with Fuzzy Pairwise Comparison. Int. J. Approximate Reasoning. 21. $215-231$

[9] Mikhailov, L., Tsvetinov, P. (2004). Evaluation of Services using a Fuzzy Analytic Hierarchy Process. Applied Soft Computing. 5. $23-33$

[10] Erensal, Y.C., Oncan, T., Demircan, M.L. (2006). Determining key Capabilities in Technology Management using Fuzzy Analytic Hierarchy Process. A Case Study of Turkey Information Science. 176. 2755 - 2770.

[11] Dubois, D. and Prade, H. (1980). Fuzzy Sets and Systems. Theory and Applications. Academic Press. New York.

[12] Chen, S.J. and Hwang, C.L. (1992). Fuzzy Multiple Attribute Decision Making. Methods and Application. Springer. New York. 